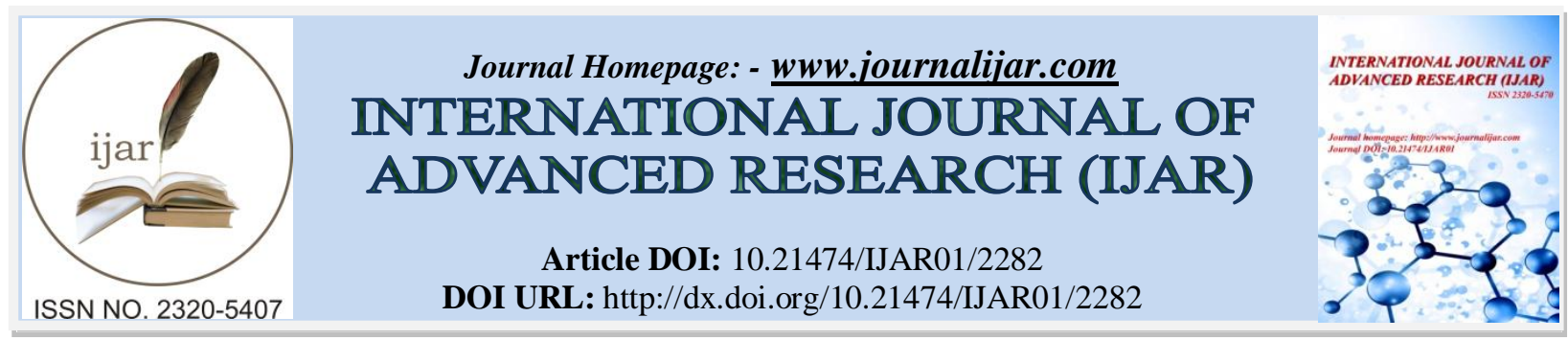

RESEARCH ARTICLE

\title{
EFFECT OF BIOFERTILIZERS (AZOTOBACTER, PSB AND THEIR COMBINATION) ON NODULATION OF TWO CULTIVARS (G-65 \& S-12) OF PHASEOLUS AUREUS ROXB. VAR. RADIATA (GREEN GRAM).
}

\author{
Dr Javaid Ahmad Khan ${ }^{1 *}$, Dr Ajaz Ahmad Banday ${ }^{2}$ and Dr Zia-ul-Hasan ${ }^{3}$. \\ 1. Deptt. of Botany, Saifia Science PG College, Bhopal (M.P.). \\ 2. Deptt. of Botany, Saifia Science PG College, Bhopal (M.P.). \\ 3. Prof.\& Head Department of Botany Saifia Science PG College, Bhopal (M.P.).
}

\section{Manuscript Info}

Manuscript History

Received: 29 September 2016

Final Accepted: 30 October 2016

Published: November 2016

Key words:-

Biofertilizers (Azotobacter \& PSB),

Phytohormones, cultivars (G-65 \& S-

12), Nodulation, fertility.

\begin{abstract}
Biofertilizers are very important in biogeochemical cycles and have been used for crop production for decades. Their interactions in the rhizosphere are the determinants of plant health and soil fertility. They help to supply nutrients to crops, to stimulate plant growth through production of phyto-hormones, to control or inhabit the activity of plant pathogens etc. The present investigation was aimed at determining the effect of individual and combination treatments of bioinoculants i.e. Azotobacter and PSB on nodulation of two cultivars G-65 and S-12 of Phaseolus aureus. Changes in the level of phytohormones were also determined in roots inoculated with biofertilizers. When different individual and combination treatments of bioinoculants were applied as seed coating treatments and it was observed that higher the doses of bio-inoculants in all the replicates, resulted in more number of nodules (nodulation) in both cultivars as compared to their controls. But it was more significant in G-65. Hence nodulation help in increasing the soil fertility, so "More the nodules more will be the fertility of soil, hence more the crop yield"
\end{abstract}

Copy Right, IJAR, 2016,. All rights reserved.

\section{Introduction:-}

Green gram is an important world food crop for providing an inexpensive source of vegetable protein (40-50\%). World production of green gram is about 1.25 million tones per annum from an estimated total area of 3.21 million hectares. The area of cultivation for green gram has been doubled in last two decades while for other cereal crops it decreased. In Thailand and Philippines, green gram is the most important legume crop. In Sri Lanka, it ranks second, while in India, Burma, Bangladesh and Indonesia, it is the 3rd most important legume crop. Green gram is a Kharif crop, well adapted to semiarid and sub humid zones with annual rain fall between $600-1000 \mathrm{~mm}$, requiring an optimum mean temperature $30^{\circ} \mathrm{C}$. It grows successfully on Sandy loam to clay loam soils, usually grown on low to medium elevations in the tropics as a rainfed crop (Ahmad \& Jan, 2001). It is a short duration crop and takes 65 120 days to mature (Smith and Roberts, 1987), that makes it suitable for various cropping systems and is cultivated primary for their dry seeds. 
Biological nitrogen fixation: In legumes, $\mathrm{N}_{2}$ fixation starts with the formation of root nodules. Rhizobium leguminasarium invade the root and resides within the cortex cell. within a week after infection, small nodules are visible with naked eye. As the nodules grow in size, they gradually turn pink to reddish in color, indicating that $\mathrm{N}_{2}$ fixation has started under field conditions, nodulation process of green gram and other legume crops are adversely affected by various soil and environmental factors such as acidic pH (Rengd, 2002), Low phosphorous (Mullen, 1988). Uneven distribution of water i.e. drought (Serrag \& Sinclair, 1998) or excessive moisture conditions (Lupwai et al., 1997) can also inhabit nodulation process. The total amount of $\mathrm{N}$-fixed through biological system was estimated to be 100-175 million metric tones per year (Ishizuka, 1992).

Biofertilizers: Biofertilizers are most advanced now-a-days and support in developing organic, sustainable, green and pollution free agriculture. Thus biofertilizers can increase the out put, improve the quality and shows excellent results in all kinds of crop plants. They enhance the attractiveness of green gram for specially different industrial markets via growth and yield attributing characters.

In the era of sustainable crop production, the plant microbe interactions in the rhizosphere play a pivotal role in transformation, mobilization, solubilization etc. of nutrients from a limited nutrient pool, and subsequently uptake of essential nutrients by plants to realize their full genetic potential. At present, the use of biological approaches is becoming more popular as an additive to chemical fertilizers for improving crop yield in an integrated plant nutrient management system.

Azotobacter is one of the important biofertilizers used world wide for crop culture. Various spp. of Azotobacter are A. agilis, A. ingrins, A. chroococum etc. out of these spp. A. chroococum is most effective and useful. Azotobacter can fix $20-30 \mathrm{Kg} \mathrm{N} / \mathrm{hec}$. and are also used to inoculate a large area of arable land in the world with the aim of enhancing plant productivity (lynch 1983). In addition, phosphate solubilizing bacteria such as species of Bacillus have been applied to soil to specifically enhance the phosphorous status of plants (Brown 1974).

The objective of this study was to see the difference in efficies of already present Rhizobium bacteria in comparison to inoculation with biofertilizers on nodulation.

\section{Material and Method:-}

The viable seeds of two cultivars G-65 and S-12 of Phaseolus aureus R. were procured from, Sehore Agricultural College, Sehore.

Biofertilizers (Azotobacter and PSB) were brought from Agro Industries, Bhopal and were used in alone as well as in combination to inoculate the plants in the experiment.

Treatments (i) (5 gm, $10 \mathrm{gm}, 15 \mathrm{gm}, 20 \mathrm{gm})$ denoted as $\mathrm{T}_{1}, \mathrm{~T}_{2}, \mathrm{~T}_{3}, \mathrm{~T}_{4}$ respectively were used in inoculation of seeds of two cultivars G-65 and S-12 (ii) PSB ( $5 \mathrm{gm}, 10 \mathrm{gm}, 15 \mathrm{gm}, 20 \mathrm{gm}$ ) denoted as $\mathrm{T}_{5}, \mathrm{~T}_{6}, \mathrm{~T}_{7}, \mathrm{~T}_{8}$ were used. (iii) combination doses of Azotobacter and PSB (5+5 gm, 10+10 gm, 15+15 gm, 20+20 gm) denoted as $\mathrm{T}_{9}, \mathrm{~T}_{10}, \mathrm{~T}_{11}, \mathrm{~T}_{12}$ respectively were also used to inoculate the seeds of two cultivars (G-65 and S-12) and (iv) were without inoculation denoted as $\mathrm{T}_{13}$.

\section{Method of Inoculation:-}

Seeds of green gram (Phaseolus aureus R.) were surface sterilized with $0.1 \%$ Mercuric chloride $\left(\mathrm{HgCl}_{2}\right)$ for 3 min. and subsequently washed in distilled water for 6-7 times. These surface sterlized seeds were moistened in sugar solution (48\%) before application of different inoculum to get a thin uniform coating of inoculum on seeds. Inoculated seeds were dried in shade before sowing (Samasegaran et al., 1982). Also 7-days after germination the seedlings in pots were also inoculated.

Number of mature nodules/plant: After 40 days of emergence, plants from three replicates were pulled out with roots, washed in distilled water and fully mature nodules (Pink colored) per plant were counted and average was computed. 


\section{Results:-}

Results showed that when the seeds and seedlings of two cultivars G-65 and S-12 were inoculated with different individual and combination doses of biofertilizers, the cultivars G-65 showed more no. of nodules, as the individual and combinations doses of biofertilizers, the cultivars G-65 showed more no. of nodules as the individual and combinations doses were increased with respect to their control. Also the S-12 on higher individual and combination treatments of biofertilizers showed significant increase in nodulation as compared to control.

Table 1:- Effect Of Azotobacter, PSB and their Combination on the Nodulation of Phaseolus aureus

\begin{tabular}{|c|c|c|c|c|}
\hline \multirow[t]{2}{*}{ S.No. } & \multirow[t]{2}{*}{ Biofertilizers } & \multirow[t]{2}{*}{ Doses } & \multicolumn{2}{|c|}{ No. of Root Nodules } \\
\hline & & & Cultivar G-65 & Cultivar S-12 \\
\hline 1. & \multirow{4}{*}{ Azotobacter } & $5 \mathrm{gm}$ & $10.50 \pm 0.93$ & $10.20 \pm 0.80$ \\
\hline 2. & & $10 \mathrm{gm}$ & $10.90 \pm 0.95$ & $10.20 \pm 0.90$ \\
\hline 3. & & $15 \mathrm{gm}$ & $11.03 \pm 0.80$ & $10.30 \pm 0.89$ \\
\hline 4. & & $20 \mathrm{gm}$ & $12.05 \pm 0.70$ & $10.60 \pm 0.85$ \\
\hline 5. & \multirow{4}{*}{$P S B$} & $5 \mathrm{gm}$ & $10.60 \pm 0.91$ & $10.20 \pm 0.93$ \\
\hline 6. & & $10 \mathrm{gm}$ & $10.90 \pm 0.95$ & $10.21 \pm 0.85$ \\
\hline 7. & & $15 \mathrm{gm}$ & $11.04 \pm 0.90$ & $10.40 \pm 0.75$ \\
\hline 8. & & $20 \mathrm{gm}$ & $11.5 \pm 0.80$ & $11.5 \pm 0.86$ \\
\hline 9. & \multirow{4}{*}{$\begin{array}{l}\text { Azotobacter }+ \\
P S B\end{array}$} & $5+5 \mathrm{gm}$ & $11.5 \pm 0.90$ & $11.5 \pm 0.85$ \\
\hline 10. & & $10+10 \mathrm{gm}$ & $11.60 \pm 0.96$ & $11.6 \pm 0.90$ \\
\hline 11. & & $15+15 \mathrm{gm}$ & $12.30 \pm 0.95$ & $11.50 \pm 0.85$ \\
\hline 12. & & $20+20 \mathrm{gm}$ & $12.80 \pm 0.85$ & $12.5 \pm 0.90$ \\
\hline 13. & Untreated & - & $10.30 \pm 0.91$ & $10.01 \pm 0.81$ \\
\hline
\end{tabular}

\section{Discussion:-}

The number of nodules increased significantly in higher doses of individual and combination treatments i.e. $20 \mathrm{gm}$. of Azotobactor, $20 \mathrm{gm}$ of PSB and $20+20 \mathrm{gm}$ of Azotobacter and PSB in both the cultivars G-65 and S-12 in presence of naturally present Rhizobium (Rhizobium leguminasarium). It might have resulted due to more competitive ability of microbes than against native rhizobial population. Since roots are the sites for microbial infection, well developed root system provide more evidence for infection resulting in greater number of nodules due to secretion of IAA and GA. Higher concentration of IAA and GA production by microbes may be another cause for more nodulation as demonstrated by Singh (1993).

Increased number of nodules recorded at higher individual and co-inoculation treatments may be due to synergistic effects of rhizobia as also noted by Yahalom et al., (1987). Lesser number of nodules is produced due to low doses of bioinoculants because there was less excretion of IAA and GA hence reduced growth of root system.

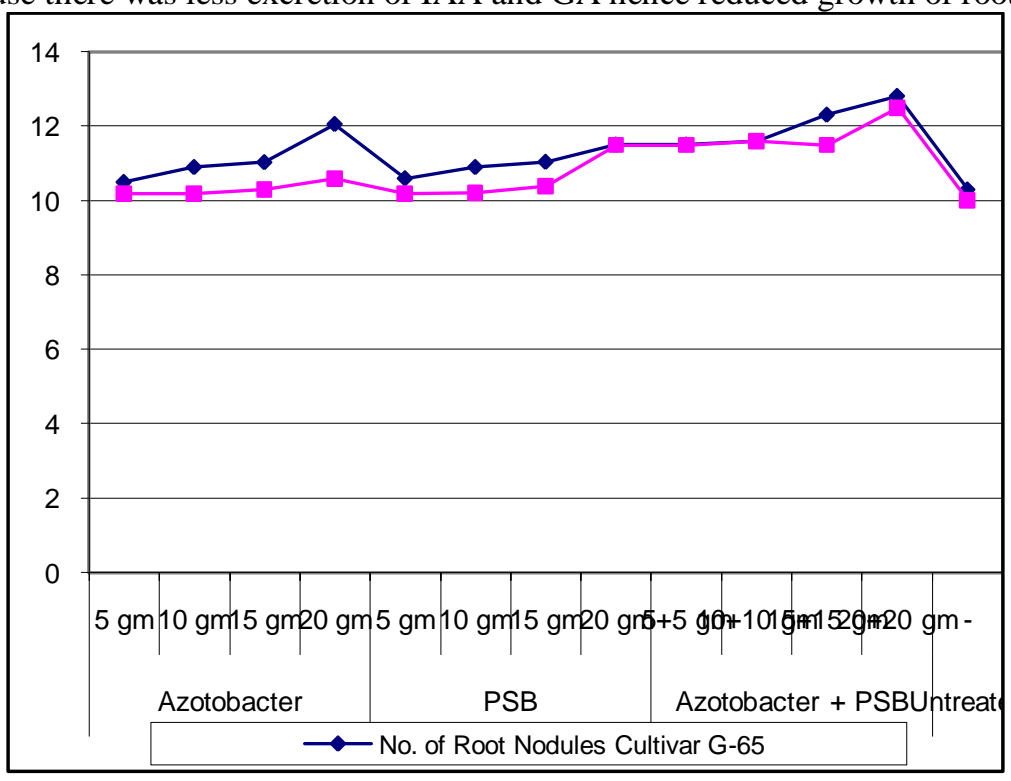




\section{NP Contents of Soil:-}

During the present investigation soil was also tested after harvest of plants for residual NP contents. Available N contents increased significantly in inoculated soil than uninoculated control. It may be due to reason that as the microbes fixes nitrogen and this nitrogen fixation suppresses nitrate uptake as demonstrated by Zarin et al., (1998). It co-relates with maximum nodulation influenced by microbes, Sing and Kumar (1989). Moreover, significant increase in $\mathrm{N}$ content may be due to the fact that legumes contribute to the total pool of nitrogen by nodulation in the soil as also observed by Ahmad et al., (2001). Some nodules get sloughed off from senescing plants at harvest and result in increased $\mathrm{NO}_{3}$ and other macro nutrients.

Higher P content may be due to inoculation and availability of $\mathrm{P}$ nutrients in soil by microbes.

\section{Conclusion:-}

Biofertilizers like Azotobacter and $P S B$, transform atmospheric $\mathrm{N}_{2}$ into amonia and increase the availability of phosphorus in the soil respectively and are central to soil and plant health. They play a pivotal role in cycling of nutrients within the soil. They benefit the growth and development of plants directly and indirectly through several mechanisms. The production of secondary metabolites i.e. plant growth substances, changes root morphology, resulting in greater root surface area for the uptake of nutrients, antagonism to soil borne root pathogens, phosphate solubilization and di-nitrogen fixation. The co-inoculating method in Phaseolus - aureus with already present Rhizobium have resulted in positive responses. As the individual and combination doses of biofertilizers (Azotobacter and PSB) were increased, the more positive effect was observed on nodulation of this crop. So we should to use biofertilizers for the proper health of plant and soil environment.

\section{Acknowledgement:-}

I am very thankful to my supervisor Dr Zia-ul-Hasan who guided and trained me in every step during experiments. Also I am thankful to Mr. Ajaz Ahmad Banday, Research Scholar of Botany, Shabir Ahmad Bhat, Research Scholar of Zoology and Rayees Ahmad Dar, Research Scholar of Biotechnology for their continuous support and assistance during experimental work.Besides Samina Saleem helped me a lot in drafting this manuscript.

\section{References:-}

1. Ahmad, I and A. Jan, 2001. Food legumes, In: Text Book of Agriculture pp: 219-24, New Millennium Edition Cropping Technology. National Book Foundation Islamabad.

2. Brown, M.E. 1974. Seed and root bacterization. Annu Rev. Phytopathol 12: 181-197.

3. Ishizuka, J., 1992. Trends in biological nitrogen fixation research and application. Pl. soil, 141: 197-207.

4. Lopawi, N.Z., I. Haque and F.B. Holl, 1997. Strain specific response of Trifolium semipilosum to inoculation with rhizobium and significance of water logging in versitols. Agric. Sci., 129: 439-66.

5. Lynch, J.M, 1983. Soil biotechnology. Blackwell, Oxford.

6. Mullen, M.D., D.W. Isreal and A.G. Wollum, 1988. Effect of Bradyrhizobium japonicum on Glycine max. phosphorous nutrition on nodulation and dinitrogen fixation. Appl. Snviron. Microbiol., 54: 2387-92.

7. Rengel, Z., 2002. Breeding for better symbiosis. Plant soil., 245: 147-62.

8. Samasegaran, P.H., Hoben and J. Halliday, 1982. The NIFTAL (Nitrogen Fixation in Tropical Agricultural Legumes) Manual for methods in legumes Rhizobium Technology. US Agency for international Development, College of Tropical Agriculture and Resources, University of Hawaii.

9. Smith, A and L. Roberts, 1987. Legume genetic resources for semi arid temperatures. Inter.Cen. Agric. Res. Dry Area ICARDA, Allepo. Syria., 363.

10. Sing, T.B. and V. Kumar, 1989. Nodulation and plant growth as influenced by growth regulators in some legumes. Acta. Bot. Indian, 17: 177-81.

11. Sing,. T.B., 1993. Effect of growth regulators on nodulation and nitrogen fixation in Vigna Mungo. Comp. Physiol. Ecol., 18: 79 - 82.

12. Serrag, R. and T.R. Sinclair, 1998. Soybean cultivar variability for nodule formation and growth under drought. Pl. Soil, 202: 159-66.

13. Yahalom, E., Y. Okon and A. Dovrat, 1987. Azospirillum effect on succeptibility to Rhizobium nodulation and on nitrogen fixation of several forage legumes. Canadian J. Microbiol., 33:510-4.

14. Zarin, F., A. Bano and M. Aslam, 1998. Effect of plant growth regulators and Rhizobium inoculum on $\mathrm{N}_{2}-$ fixation and yield of Cicer arietinum. In: Proc. 7th Int. Symp. of Nitrogen Fixation with non-legumes pp: 103-6. Kluwer Acedemic publishers, Great Britain. 